\title{
Using The Puzzle Teaching Method To Teach Home Nursing Care Concepts: An Evaluation Study
}

\section{Zahra Tayebi}

Alborz university of medical sciences

Seyede Soghra Taher harikandeie ( $\nabla$ mz.taher89@gmail.com )

Alborz university of medical sciences

Maryam Aghabarari

Alborz university of medical sciences

\section{Research Article}

Keywords: Puzzle teaching method, Nursing students, Home nursing care, Evaluation study

Posted Date: October 12th, 2021

DOl: https://doi.org/10.21203/rs.3.rs-837660/v1

License: (1) This work is licensed under a Creative Commons Attribution 4.0 International License. Read Full License 


\section{Abstract}

Background: One of the participatory learning approaches is the puzzle teaching method. Depending on the nature of the subject and the type of learners, this strategy can produce a variety of outcomes. The purpose of this study was to see how well the puzzle teaching style worked in the undergraduate nursing program's home nursing care course.

Methods: This is a three-year evaluation study utilizing a qualitative methodology that took place between 2016 and 2019. The teaching technique was employed for a number of sessions of a home nursing care course during the first phase, and an evaluation was conducted at the end of the course using purposive sampling and focus group interviews with 11 students. The results of the first phase's evaluation led to changes in the procedure in the second phase, and at the end of that course, the evaluation was repeated with the 13 students. Further modifications to the teaching style were made, and a re-evaluation with ten students was conducted. MAXQDA10 software was used to conduct traditional content analysis on the data.

Results The benefits of the puzzle method were confirmed by participants, but the findings of the first two phases of evaluation revealed obstacles such as "ineffective involvement," "inadequate teacher supervision," "offering unnecessary content," and "lack of final summarization" by the faculty member, "ineffective involvement", "crowded classroom", "the need for evaluation "and "piece learning" . Except for "ineffective involvement," the third phase's evaluation findings suggested that all flaws and obstacles had been addressed.

Conclusion: The majority of the obstacles to implementing the puzzle teaching approach can be overcome by changing a few stages and procedures. However, ineffective involvement remains a significant roadblock. To overcome this stumbling block, more research is required.

\section{Background}

\section{Background}

Education is one of the most basic human necessities and a critical component of a country's long-term growth (1), and undervaluing it can result in a waste of resources $(2,3)$. Different components of education are influenced by a variety of individual and contextual factors, including instructional content, content structure, learner motivation, and teacher-learner interaction, but teaching methods have a significant effect (4).

Concerns concerning the quality of nursing education have been raised in recent decades as nursing education has become more integrated into the higher education system $(2,3,5)$. Most universities are seeking for novel educational techniques to enhance clinical decision-making capacities as well as continuous and knowledge-based learning for nursing students, as educational methods used in nursing education can play an essential role in nursing professionalism (2). 
As we progress toward new teaching approaches, we're putting more focus on the human paradigm, which has led to more active teaching models being used. We can point to group teaching structures as an example of active teaching models, with the participatory teaching model being the most essential $(6,7)$. The teacher maximises learning in the participatory learning technique by providing proper context and conditions for learning, as well as encouraging and convincing the students (8). The puzzle learning method is one of the participatory learning approaches. In response to educational issues, Arnson et al (1970) devised this teaching style. Learners are placed into numerous groups in this system (usually 4 to 5 people). After then, one individual from each group is assigned to study the subject. Similarly, the content is dispersed among the members of each group. The teacher allots time for students to study. People from each group who have a similar theme get together at the conclusion of the time to establish a new group (expert group). At a certain time, they share their understanding on the subject. Eventually, each person returns to their original group (home group) to teach the other members of their group what they have learned $(1,9)$.

Numerous research comparing the puzzle teaching method to different educational methods have been undertaken. In some trials, the educational outcomes were the same for both strategies, but in others, one method was more effective than the other. Phillips and Fusco's (2015) study is one of the most important related studies. The findings of this study revealed that the puzzle approach elicited a high level of student participation, and the majority of students believed that this method provided slightly more learning than other interactive methods (10). Sanai et al. (2019) found that In comparison to the lecture technique, the puzzle method not only fostered self-regulated learning, but also contributed to students' academic success (2). However, according to a study by Leyva-Moral and Riu Camps (2016), the puzzle technique does not result in more learning than traditional learning methods, but it does help learners to improve teamwork skills and interpersonal relationships (11). The effect of the puzzle technique and the lecture method on students' knowledge is the same, according to RahimKhani and Shirazi (2015), but the puzzle approach encourages students to participate in discussions and exchanges with teachers and other students. It also encourages students to study books and other external sources; on the other hand the teacher's ability to manage the classroom is higher in the lecture technique, and the order of presenting the educational materials is better conserved (12). The combination of these contradictory data points to the necessity for a study using an evaluation design to explain and remedy the difficulties and flaws. As a result, the purpose of this study was to assess the application of the puzzle teaching approach in a nursing program's home nursing care course over the duration of three years.

\section{Objectives:}

This study aimed to evaluate the implementation of puzzle teaching method in the home nursing care course of undergraduate nursing program, The research questions were as follows: first, what is the experience of nursing students in implementing the puzzle teaching method? second, What are the characteristics of the puzzle teaching method from the perspective of nursing students? and third, What

are the factors affecting nursing students' understanding of the features of the puzzle teaching method? 


\section{Methods}

Ethics statement: This study was approved by the Ethics Committee of Alborz University of Medical Sciences (IR. ABZUMS.REC.1389.095). Informed consent was obtained from participants.

\section{Study design:}

This is an evaluation study that was conducted on third-year undergraduate nursing students to see how well the puzzle teaching approach was implemented in the nursing program's home nursing care course. The goal of evaluation studies is to gather relevant information on a programme or technique that will aid planners in deciding whether to adopt, change, or discontinue it. The purpose of evaluation is to answer a variety of questions and to investigate the subject. As a result, both quantitative and qualitative data must be collected. The results of experimental and quasi-experimental studies are used to answer questions about programme efficacy, but we require a qualitative technique to address the remaining problems. Typically, the following questions are raised in this type of research: Is there a difference between this intervention's implementation and the typical and traditional methods? What are the obstacles to the program's successful implementation? Is the programme working the way it was supposed to? What are the opinions of the participants in the programme? What is it that they enjoy the most about it? As a result, qualitative data is crucial in process analysis $(13,14)$.

\section{Setting}

This study was conducted on third year undergraduate nursing students in order to evaluate the implementation of puzzle teaching method in the home nursing care course of nursing program.

\section{Participants:}

Because the intervention in this study was related to one of the undergraduate nursing curriculum's courses, all (145) third-year undergraduate nursing students took part in it. 34 students consented to engage in focus group discussion through purposeful sampling.

\section{Intervention}

According to the references, the Corresponding author created the puzzle teaching method (9). The course was created so that each semester, a number of themes for puzzle sessions would be chosen based on their substance, and a number of lecture sessions would be held (table 1). Several puzzle subjects were chosen such that students were already familiar with the pathophysiology, signs, symptoms, treatment, and nursing care associated with them. This course (home nursing care) focused on how to deliver helpful and effective nursing care to patients in their homes. A briefing session with the students was organized at the start of the course to explain how to implement the method. Learners were divided into numerous groups to utilize this instructional strategy (usually 4 to 5 people as home groups). The contents were then dispersed among the persons in each group, and several subjects were assigned to one person in each group to study. The teacher set aside time for the students to study (20 to 30 
minutes). After a period of time had passed, the members of each group who shared a common interest created a new group (expert group) and shared their expertise of the subject within a certain time limit (15 to 20 minutes). Finally, each person returned to his or her original group (home group) and presented his or her topic to the rest of the group $(4,9)$. The obstacles posed by the pupils were assessed after each phase, according to the evaluation, while keeping the essential principles of the puzzle approach. The course plan was changed and modified at each phase based on the findings of the participant interviews. The resulting teaching method resembled the TMTD (Team Member Teaching Design) method in many ways. All of the phases in the TMTD technique are identical to those in the puzzle method, with the exception that at the end of the session, the learning is assessed through a comprehensive exam covering the entire topic. A number of questions are posed in this manner, and students are given a set amount of time to respond to them. Individual scores and the grade point average are calculated at the end of the response period. (15). (Table 2)

\section{Data collection}

Data was collected between 2016 and the beginning of 2019. Because the intervention was carried out in three stages (in the autumn semester of each year), the evaluation data was likewise collected in three stages.

- First phase: The evaluation data was obtained at the end of the course through two focus group interviews with 7 and 4 students in the classroom, respectively. At this stage, focus group interviews lasted an average of 60 minutes.

- Second phase: Students who were interested in participating in the interview were invited once the programme was completed in the second phase. 6 and 7 kids were divided into two focus groups. In both focus groups, the average interview time was 75 minutes.

- Third phase: Final focus group interviews (two groups of 7 and 3 people, respectively) were done with new participants who had been taught the approach in the third phase. In both focus groups, the average interview time was 75 minutes.

The group interviews were moderated by the first author, who had no role in teaching the themes. The interviews began with a broad question: "Describe a typical day of learning in a puzzle-based classroom." Members of the focus group took part in the conversation and were asked the following questions based on the responses and reactions of the participants (Table 3). ). In general, the questions were on identifying the barriers to using this teaching approach, the differences between the new and traditional teaching methods, and students' perceptions of the programme. A voice recorder was used to record the interviews.

\section{Data analysis}

Interviews were taped with the participants' agreement and consent, and then transcribed verbatim. With the help of MaxQDA10 software, recorded and transcribed interviews were evaluated using a traditional content analysis method. Following each interview, the interview material was read numerous times to 
gain a general knowledge of its content.The hidden semantic units in the text were then identified and coded in the next stage. Following that, the codes were divided into subgroups based on their similarities and differences, resulting in the primary groupings (16).

\section{Rigor}

During the first coding process, the member checking approach was utilized to confirm the rigour. As a result, the codes and interpretations derived from the interview analysis were double-checked with a group of participants. In addition, peer review was done to ensure that the coding procedure was accurate. In addition, the entire data collection and analysis procedure was accurately and thoroughly detailed. The researchers stayed in the field long enough to collect all of the data and reach the saturation point in order to further validate their findings.

\section{Ethical considerations}

The other authors were involved in the data gathering procedure because the Corresponding author of the article was the lecturer of the relevant course and, in reality, she performed the study intervention. Another thing worth mentioning is that the interviews took place after the course's final test and grades were recorded. By assigning a code to each participant in the focus groups, the data's secrecy was maintained.

\section{Results}

34 students (the majority of whom were female students) entered the assessment study and participated in the focus groups out of the 145 who took part in the project (Table 4). The participants were 21 years old on average, with a grade point average ranging from 19.14 to 13.62 . This evaluation study's findings can be presented in three stages. Table 5 shows the emerging categories, with the details of the findings reported separately in each phase. It's important to note that the findings concentrated on the problems of adopting this teaching technique, followed by corrective measures at each level, as stated in the study's goal.

\section{Phase 1:}

During this step, the data collected from the interviews was analyzed and the following categories were identified:

Ineffective involvement: Because the instructional content was spread among the students in the home group, participants' experiences revealed that some kids were not accepting their fair share of responsibility and were unprepared. As a result of the lack of sufficient preparation, the topic was presented in an incomplete manner. This issue is viewed by students as a significant impediment to reaching educational goals in this teaching technique. 
"Although there was a task for everyone in this technique, and they all had to complete it, some pupils did not do their jobs effectively, causing a difficulty for the entire group. They didn't take it seriously and showed up unprepared in class."

"Some of the students had not read the text before and entered the classroom, which made them not fluent in their own section, and they just came to read the text. This created a vacuum in the group".

Inadequate teacher supervision: Because the entire teaching and learning process in this technique took place in groups, $\mathrm{h}$ and e, participants judged that inadequate teacher supervision had a detrimental impact on accomplishing learning goals. In other words, inadequate teacher monitoring resulted in ineffective technique implementation.

"Because the teacher was unaware of what was going on in the groups, the approach was not executed well in some of them, especially in the early sessions, when we were still getting to know each other, which was disconcerting. It would have been beneficial if the teacher had spent a few minutes with each group, for example, to observe what they were doing."

providing unneeded content: The incapacity of students to supply content that was consistent with educational goals was an issue that might be considered in the experiences of participants. This inconsistency could present itself in the form of omitting crucial topics or providing unneeded content.

"The content had to be prepared by us. We didn't know whether parts of the content were crucial and, in reality, comprised the main themes, and which were less so. As a result, occasionally the substance offered was uninteresting, and, of course, some crucial issues were presented wrongly".

Ineffective communication: Participants had a negative experience dealing with the teacher and considered that this had an impact on the method's quality of execution.

"We had never seen the teacher before, and the manner was unfamiliar, so everything appeared to be complex. We couldn't always develop the essential dialogue and involvement in the classroom, which made us feel bad and scared".

Intra-group communication challenges: Because of the communication that existed between students prior to the introduction of the approach, the teacher's establishment of default groups was accompanied by complaints from the participants at random. The pupils believed they couldn't communicate with their peers, which contributed to the method's failure to achieve its objectives.

"The ties that students already formed with one another in the group sometimes had a negative impact on their productivity. For example, some of them already had issues with one another and did not enjoy working together, which harmed their job. I believe it is more preferable to allow pupils to form their own groups". 
Lack of a final ending: One of the participants' common impressions was that the concepts in each session lacked a final conclusion. There was no methodology for summarizing and closing the educational concept in each session according to the original model of the puzzle technique, and this issue caused students to have difficulty concluding the educational concept in each session.

"As if there was an empty space in our heads, we couldn't figure out how the session would conclude." We needed the teacher to give us a conclusion at the end of the session and to clarify the areas that we were having difficulty understanding. This, however, did not occur. At the end of each lecture session, we are given the opportunity to ask questions".

\section{Phase 2}

Following the revisions and implementation of the model, a second evaluation was conducted using focused interviews with students. Some of the issues from the previous phase, such as the lack of a definite conclusion and the content's inconsistency with educational goals, were resolved, while others remained. The following themes emerged from this phase's analysis:

Ineffective involvement: The interviewers still faced a severe issue in not taking the session and instructional approaches seriously. The learning process was hampered by certain students' unwillingness to participate in group work and their lack of collaboration in supplying content.

Group heterogeneity: Although the problems of intra-group communication amongst students were reduced at this stage, the issue of group members' educational level heterogeneity was mentioned as one of the challenges.

"The situation among the groups was different. For example, because the group members were chosen from the classroom list, one group was made up entirely of smart students, while the other was made up entirely of non-smart children. It was preferable to have smart, average, and weak pupils in each group."

Crowded classrooms: Because there were more people in the school at this era, crowding classrooms was another issue that was added to the issues. Putting a large number of pupils in small groups in a short space generated overcrowding and disturbed the learning process. This issue did not arise in the first phase since there were fewer studs in the first phase.

"Our class had a total of 53 students. Assume we were in groups of six or seven, and when these groups began to converse, the classroom became extremely noisy, which bothered us much. We couldn't always hear each other."

Piece learning: Students' objections regarding a portion of each teaching session's material arose as a new difficulty in this phase, leading to revisions in the third phase. In reality, pupils simply learned the topics that they needed to prepare for. They didn't learn the rest of the material for a variety of reasons, including other group members' incapacity to convey the points, and their own lack of readiness to express it. 
"When you sit in a lecture-style classroom, you hear everything the teacher has to say, but with this method, I just learned what I had prepared. However, I was having trouble understanding the bits that other students were presenting, which scared me that the exam would be difficult."

\section{Phase 3}

Other improvements in the implementation of the teaching approach were made as a result of the second phase's analysis of assessment data. The third phase evaluation was conducted through focus group interviews with learners after the model was re-implemented, following the changes made to weak points discovered in the second phase. Many of the difficulties that teachers face were addressed. However, several aspects remained a challenge, such as ineffective involvement. Given that this was the study's final phase, the key points extracted from student interviews after implementing three phases of the method and making corrections, such as teaching through peers, creating a dynamic and appealing classroom, and establishing new interactions between students, were introduced as positive features of the proposed method.

\section{Discussion}

\section{Key results}

The purpose of this study was to see how effective the puzzle teaching method was in implementing a home nursing care course for third-year nursing students. This course was recently added to the nursing program's curriculum in Iran, and because to the nature of the content, a different approach was required, therefore it was chosen.

Unlike many other research that concentrated on the positive aspects of this teaching technique $(2,11)$, the findings of this study focused on the problems and impediments to applying it. As a result, this research was carried out spanning three years and three different admission times for students.

According to the experiences of participants in this study, one of the problems of adopting the puzzle teaching technique in the initial phase was a lack of efficient communication between the teacher and the students, as well as insufficient teacher monitoring in the classroom. According to the experiences of participants in this study, one of the problems of adopting the puzzle teaching technique in the initial phase was a lack of efficient communication between the teacher and the students, as well as insufficient teacher monitoring in the classroom. During the first phase of the implementation, participants believed that their relationship with the teacher was not established. Individual and contextual factors, such as educational content, how it is organised, the number of educational activities, learner motivation, and how the teacher and student interact, all influence the level of learning. The teacher's teaching technique plays a particular and unique significance in this regard (17). The efficiency of this teaching approach can be increased by the teacher's familiarity and mastery of the puzzle teaching method, as well as the students' cooperation in its implementation $(4,17)$. This is one of the reasons why many teachers are hesitant to adopt interactive approaches in the classroom at first. Teachers' reluctance to use 
participatory methods in the classroom is due to a variety of factors, including a lack of familiarity with new teaching methods, a reduction in classroom control, a lack of confidence in classroom management, and a fear of heterogeneous learner participation and not fully covering the content. However, when they develop experience in this field, they are pleasantly and unexpectedly welcomed with favorable feedback from students, encouraging them to continue using this strategy (18). The examination of data from participants' experiences in the second and third stages of the study revealed that the instructor, after a year of experience teaching with the puzzle technique, was able to identify and manage the issues identified in the first phase of the study. As a result, throughout the second and third stages of the study, the difficulties linked to classroom management were addressed. Another problem in adopting the puzzle teaching method, as mentioned by study participants during the second round of evaluation, was a crowded classroom. A review of the texts revealed that the huge number of students in the groups, the absence of enough physical space, and the lack of basic facilities for the right arrangement of chairs were all effective aspects that negatively influenced the students (19). This problem was overcome in this study by separating the students into two groups and holding sessions on different days for each group.

The ineffective involvement of students in the classroom was noted as one of the challenges and hurdles to the adoption of the puzzle teaching approach in all three phases of evaluation. Participatory learning is the core of the puzzle teaching approach, which is one of the student-centered and active learning methods. This means that learners try to improve their own and other group members' learning capacities in order to attain joint goals. As a result, the importance of teamwork and a sense of responsibility in the learning process by students is critical in this method $(2,11)$. Because the most important prerequisite for using this teaching method is individual students' cooperation and participation in accepting and implementing their learning responsibilities, if a student fails to do so, he or she will make the process of teaching and learning difficult for himself, other members of the group, and finally the entire class. As a result, pupils' learning will suffer, as will their pleasure with this teaching technique. On the other hand, it should be noted that using a participatory teaching style necessitates mental preparation on the side of the students. Learners are often unaccustomed to participatory teaching methods and prefer to acquire lessons directly from their teachers as a result of long-term use of passive and especially nonparticipatory methods such as lectures $(3,20,21)$. This might lead to the assumption that teaching is the teacher's job and that students should not do the teacher's job over time (11). Of course, factors such as students' lack of interest in the field of study and its educational content, as well as holding the sessions at inconvenient times, particularly in the evening and following the morning internship programme, can all be considered effective factors in learners' ineffective participation in the puzzle implementation (21). However, studies demonstrate that proper implementation, follow-up, and long-term use of this teaching style can boost students' motivation, cooperation, and team engagement $(2,10,11,22)$. The results of research suggest that if the teacher has the requisite skill and motivation to follow this strategy, the learners' motivation and responsibility will grow over time $(11,25)$. However, some of the difficulties can be attributable to the puzzle teaching approach itself. In the original version of the puzzle method, for example, there is no final conclusion, and the teacher uses the reference protocol to implement the 
technique. In this study, after identifying the problems, the teacher addressed the issue (lack of a definitive conclusion) by altering the implementation.

Peer learning, a lively and appealing classroom, and the establishment of new contacts between students were among the good elements of the puzzle teaching approach, according to the participants, notably in the second and third stages of the study. A review of the literature revealed that puzzle teaching approaches are used in a variety of areas, including mathematics (26), computer programming (27), medicine $(7,28)$, nursing $(2,11)$, dentistry $(29)$, pharmacy $(10)$, language learning $(4)$, has been linked to positive outcomes such as increased knowledge and student satisfaction, increased learning, interest and motivation, academic achievement, self-regulatory learning, group participation, social skills, teamwork skills, and peer learning. (25). In other words, if applied effectively and in accordance with the content and educational goals, this teaching style has been demonstrated to be beneficial in accomplishing educational goals. As a result, unfavorable results from this approach in specific courses can be linked to reasons such as teachers' and students' unfamiliarity with this teaching style, a lack of cooperation, and students' resistance to changes in the type of teaching method, teachers' incompetence and lack of expertise with this approach, students' lack of understanding about the aims, features, and steps of the puzzle teaching method, students' lack of skills to engage in the puzzle teaching method discrepancy between the type and quantity of instructional content chosen and the time required to present it, a class with a big number of students $(3,17)$. In this regard, it is critical to consider teaching approaches realistically, as each has advantages and disadvantages that should be selected and executed based on the nature of the subject, the target population, and the teacher's characteristics.

\section{Conclusion}

According to the findings of this study, using the puzzle teaching approach can pose obstacles for both the teacher and the learner. Learner ineffective involvement, crowded classrooms, piece learning, and a lack of final ending are among the most significant of these issues. However, the results of this evaluation study revealed that the problems were mainly remedied with the passage of time and the correction of challenges by identifying and resolving hurdles to the right execution of this strategy through student input. The use of this teaching approach in combination with other methods such as interactive lectures, group discussions, questions and answers, summarization and evaluation at the end of teaching sessions is advised, according to the findings of this study.

\section{Declarations}

\section{Ethics approval and consent to participate}

This study was approved by the Ethics Committee of Alborz University of Medical Sciences (IR. ABZUMS.REC.1389.095).

In this study, written consent was obtained from all participants and all of them signed the consent form. 
all methods were performed in accordance with the relevant guidelines and regulations by including a statement in the Declarations section to this effect.

\section{Consent for publication}

Not applicable

\section{Availability of data and materials}

To access the data of this study, you can contact the first author (tayebi2010@hotmail.com).

\section{Competing interests}

The authors declare that they have no competing interests.

\section{Funding}

Alborz university of Medical Sciences funded this study

\section{Authors' contributions}

ST designed the study, implemented the intervention and also was a major contributor in writing the manuscript.

ZT designed the study, collected and analyzed data and also was a major contributor in writing the manuscript.

MA contribute to data analyzing and also was a major contributor in writing the manuscript.

All authors read and approved the final manuscript.

\section{Acknowledgements}

Not applicable

\section{References}

1. Hannani S, Samii N, Khacian A. Comparison of Traditional and Jigsaw Teaching Methods on Learning and Perception of Learning Environment of Operating Room Students of Iran University of Medical Sciences. 3 JNE. 2019; 8 (5):39-46. (in Persian).

2. Sanaie N, Vasli P, Sedighi L, Sadeghi B. Comparing the effect of lecture and Jigsaw teaching strategies on the nursing students' self-regulated learning and academic motivation: A quasiexperimental study. Nurse Educ Today. 2019;79:35-40. doi: 10.1016/j.nedt.2019.05.022.

3. Haghighat M, Sabety F, Tahery N, Haghighizadeh M. Comparison the Efficacy of Lecture and Cooperative Teaching Method such as Jigsaw Puzzle on Learning and Satisfaction within Nursing 
Students. Jundishapur Educ Develop Quarterly. 2014;5(3):14-22. (in Persian).

4. Nugroho KY, Fitri K. The effectiveness of jigsaw learning strategy to improve students reading ability. Journal of English Education, Literature and Culture. 2016; 68-75.

5. Kayzouri A., Sadeghpour M. A Comparison on the Effects of Traditional, E-learning and Traditional-E learning on the pharmacology course of nursing students. Journal of Sabzevar University of Medical Sciences. 2017; 24(2): 123-127. (in Persian).

6. Abrami PC, Bernard RM, Borokhovski E, Waddington DI, Wade CA, Persson T. Strategies for Teaching Students to Think Critically: A Meta-Analysis. Review of Educational Research. 2015;85(2):275-314. doi:10.3102/0034654314551063

7. Goolsarran N, Hamo C.E, Lu WH. Using the jigsaw technique to teach patient safety. Med Educ. Online 2020; 25, 1710325. DOI: 10.1080/10872981.2019.1710325.

8. Ahmad AR., Seman AA, Awang MM \& Sulaiman F. Application of Multiple Intelligence Theory to Increase Studen-tMotivation in Learning History. Asian Culture and History. 2015; 1(7):210-219.

9. Xu JH.Toolbox of teaching strategies in nurse education. Chinese Nurs Res. 2016; 3:54-57. doi: 10.1016/j.cnre.2016.06.002.

10. Phillips J, Fusco J. Using the Jigsaw Technique to Teach Clinical Controversy in a Clinical Skills Course. Am J Pharm Educ. 2015;79(6):90. doi: 10.5688/ajpe79690.

11. Leyva-Moral JM, Riu Camps M. Teaching research methods in nursing using Aronson's Jigsaw Technique. A cross-sectional survey of student satisfaction. Nurse Educ Today. 2016;40:78-83. doi: 10.1016/j.nedt.2016.02.017.

12. Rahimkhani M, Shirazi M. Comparison of training methods on student learning levels. Laboratory \& Diagnosis. 2015; 7 (27):40-46 (in Persian).

13. Polit. Denis, F. Nursing research. Wolters Kluwer/Lippincott Williams \& Wikins.2017: 238-239.

14. Polit. Denis, F. Essentials of nursing research. Wolters Kluwer/Lippincott Williams \& Wikins. 2018: 218.

15. Karami M, Saeedipoor B, sarmdi M, farajollahi M. Comparing the Impact of Team Memebers Instruction on Students' Learning-Teaching with Restatement Teaching Method: The Case in Ilam Farhangyan University. Research in Curriculum Planning. 2018; 14(55): 111-123. (in Persian).

16. Vaismoradi M, Turunen H, Bondas T. Content analysis and thematic analysis: Implications for conducting a qualitative descriptive study. Nurs Health Sci. 2013 Sep;15(3):398-405. doi: $10.1111 /$ nhs. 12048.

17. Adib-Hajbaghery M, Rafiee S. Comparing the Effectiveness of Group Discussion and Lecture Methods on the learning of medical sciences students: A Review Study. Iranian Journal of Medical Education. 2016; 16:53-62 (in Persian).

18. Sadeghnezhad forotagheh M, Bagheri M. Comparison of Lecture and Puzzle for Teaching Medical Emergency to Anesthesiology Students: Students' Learning and Viewpoints. Iranian Journal of Medical Education. 2013; 12 (10):786-795. (in Persian) 
19. Fallahi E, Farhadi A, Ghazi S. Effect of Modified Team Effect of Design(m-TED) and lecture teaching methods on students' satisfaction and their learning in Lorestan University of Medical Sciences. Biannual J Med Edu, Education Development Center, Babol University of Medical Sciences 2013; 1(1): 7-12(in Persian).

20. Voyles, E., Sarah F. Bailey and A. Durik. "New Pieces of the Jigsaw Classroom: Increasing Accountability to Reduce Social Loafing in Student Group Projects." The New School psychology bulletin. 2015;13: 11-20.

21. Torabizadeh K, Fathiazar E, Rahmani A. The Effect of Two Teaching Methods on Nursing Students Perception of Psycho-Social Climate of the Classroom: Jigsaw Puzzle Versus Programmed Lecture. Iranian Journal of Medical Education. 2010;9(4):290-301. (in Persian).

22. Halimah L., Sukmayadi V. The role of "jigsaw" method in enhancing Indonesian prospective teachers' pedagogical knowledge and communication skill. International Journal of Instruction. 2019;12(2):289-304.https://doi.org/10.29333/iji.2019.12219a

23. Jahan F, Siddiqui MA, Aguiar MR. Innovation in clinical teaching: diabetic foot care management using jigsaw teaching strategy in family medicine. Isra Med J. 2019; 11(3): 171-174.

24. Muenks, Katherine et al. "How True Is Grit? Assessing Its Relations to High School and College Students' Personality Characteristics, Self-Regulation, Engagement, and Achievement." Journal of Educational Psychology. 2017;109: 599-620.

25. Karimi Moonaghi H, Bagheri M. Jigsaw: A good student-centered method in medical education. Future of Medical Education Journal. 2017;7(1):35-40.

26. Abed AZ, Sameer SA, Kasim MA, Othman AT. Predicting Effect Implementing the Jigsaw Strategy on the Academic Achievement of Students in Mathematics Classes. INT ELECT J MATH ED. 2020;15(1):em0558. https://doi.org/10.29333/iejme/5940

27. Tekdal M, Sönmez S. The Effect of Using Jigsaw Cooperative Learning Technique in Teaching Computer Literacy on Students' Achievement and Retention. Cukurova University Faculty of Education Journal. 2018; 47(1): 37-59.

28. Jafariyan M, Matlabi M, Esmaeili R, Kianmehr M. Effectiveness of teaching: Jigsaw technique vs lecture for medical students' Physics course. Bali Medical Journal. 2017;6(3):529. doi: 10.15562/bmj.v6i3.400.

29. Momeni Danaei Sh, Zarshenas L, Oshagh M, Omid Khoda SM. Which method of teaching would be better; cooperative or lecture? Iranian Journal of Medical Education. 2011;11(1):24-31. (Persian).

\section{Tables}

Table 1-Separation of topics in the classroom 


\section{Topics presented in the form of lectures Topics presented in the form of puzzle}

Home care of a patient with spinal cord Home care of a patient with hypertension injuries

Home care of a breast cancer patient

Home care of a patient with prostate cancer

Home care of patient with ostomy

Home care of a patient with an artificial airway

Wound care
Home care of a patient with myocardial infarction

Home care of a patient with heart failure

Home care of a patient with stroke

Home care of a patient with diabetes

Home care of a patient with chronic obstructive pulmonary disease

\section{Table 2-The modifications}

After the first phase and beginning of second phase

After the second phase and beginning of third phase
Preparing educational content by the instructor

Summarizing at the end of each topic by the instructor, and questions and answers with students to resolve the problems

More teacher supervision over the groups to ensure the correct implementation of teaching method

Dividing the groups into two groups and working with them on two different days to reduce crowding

Holding an exam and determining individual scores and average team scores, and also offering rewards

Designing groups based on students' academic characteristics (grade point average)

Table 3- Examples of interview questions 


\section{Interview questions}

How was your experience of puzzles teaching method?

What distinguishes a puzzle method from a lecture?

What suggestions do you have for better implementation of puzzle method?

Table 4- characteristics of focus groups

\begin{tabular}{|llll|}
\hline $\begin{array}{l}\text { Total number of } \\
\text { students }\end{array}$ & $\begin{array}{l}\text { Number of focus } \\
\text { groups }\end{array}$ & $\begin{array}{l}\text { Number of students in each } \\
\text { group }\end{array}$ & $\begin{array}{l}\text { Average interview } \\
\text { duration }\end{array}$ \\
\hline 38 & 2 & $\begin{array}{l}\text { Group 1 }(n=7) \\
\text { Grou2 1 }(n=4)\end{array}$ & 60 min \\
\hline 53 & 2 & Group 1 $(n=6)$ & 75 min \\
& & Grou2 1 $(n=7)$ & 75 min \\
\hline 54 & 2 & Group 1 $(n=7)$ & \\
\hline
\end{tabular}

Table 5- Extracted categories resulted from the analysis

\begin{tabular}{|lll|}
\hline Phase 1 & Phase 2 & Phase 3 \\
\hline Ineffective involvement & Ineffective involvement & Ineffective involvement \\
\hline Inadequate teacher supervision & & \\
\hline Providing unneeded content & Crowded classroom \\
\hline Ineffective communication & \\
\hline Lack of a final ending & Group heterogeneity \\
\hline Intra-group communication challenges & Piece learning \\
\cline { 2 - 2 } & The need for evaluation \\
\cline { 2 - 2 } & \\
\hline
\end{tabular}

